\title{
Synthesis, docking study and biological evaluation of D-fructofuranosyl and D-tagatofuranosyl sulfones as potential inhibitors of the mycobacterial galactan synthesis targeting the galactofuranosyltransferase GIfT2
}

\author{
Marek Baráth ${ }^{* 1}$, Jana Jakubčinová ${ }^{1}$, Zuzana Konyariková2 ${ }^{2}$ Stanislav Kozmon ${ }^{* 1}$, \\ Katarína Mikušová ${ }^{2}$ and Maroš Bella ${ }^{1}$
}

\author{
Full Research Paper \\ Address: \\ ${ }^{1}$ Institute of Chemistry Slovak Academy of Sciences, Dúbravská cesta \\ 9, SK-845 38 Bratislava, Slovakia and ${ }^{2}$ Department of Biochemistry, \\ Faculty of Natural Sciences, Comenius University in Bratislava, \\ Ilkovičova 6, SK-842 15 Bratislava, Slovakia \\ Email: \\ Marek Baráth* - chemmbar@savba.sk; Stanislav Kozmon* - \\ stanislav.kozmon@savba.sk \\ ${ }^{*}$ Corresponding author \\ Keywords: \\ GIfT2; molecular modeling; mycobacterium tuberculosis; synthesis; \\ transition state inhibitors
}

Beilstein J. Org. Chem. 2020, 16, 1853-1862.
doi:10.3762/bjoc. 16.152
Received: 30 April 2020
Accepted: 09 July 2020
Published: 27 July 2020
The article is dedicated to Prof. Ladislav Petruš on the occasion of his
70th birthday.
Associate Editor: J. S. Dickschat
(C) 2020 Baráth et al.; licensee Beilstein-Institut.
License and terms: see end of document.

\begin{abstract}
A series of ten novel D-fructofuranosyl and D-tagatofuranosyl sulfones bearing a 1- $O$-phosphono moiety and three different substituents at C-2 has been prepared. Due to the structural similarities of these scaffolds to the native substrate of mycobacterial galactofuranosyltransferase GlfT2 in the transition state, we evaluated these compounds by computational methods, as well as in an enzyme assay for the possible inhibition of the mycobacterial galactan biosynthesis. Our data show that despite favorable docking scores to the active site of GlfT2, none of these compounds serve as efficient inhibitors of the enzymes involved in the mycobacterial galactan biosynthesis.
\end{abstract}

\section{Introduction}

Tuberculosis (TB) is one of the most prevalent infectious diseases, with estimated 10 million new cases each year. It causes about 1.5 million deaths annually and is amongst the top 10 causes of death worldwide. The emergence of multidrugresistant and extensively drug-resistant TB has become a major public health concern as the success rate of the treatment in these cases is only $56 \%$ and $39 \%$, respectively [1]. Clearly, the need for new and more efficient TB drugs is pressing. Among the novel therapeutic agents developed for TB, there are several compounds that target the cell wall of Mycobacterium tuberculosis, the causative agent of the disease [2]. The mycobacterial cell wall core is formed by the mycolyl-arabinogalactan-peptidoglycan (mAGP) complex, which provides a highly hydrophobic and resistant barrier surrounding the bacterium [3]. The 
galactan component of the cell wall consists of polysaccharide chains composed of approximately 22 galactofuranose (Galf) residues linked by alternating $\beta$ - $(1 \rightarrow 5)$ - and $\beta$ - $(1 \rightarrow 6)$-glycosidic bonds [4]. The Galf monomer is restricted to some bacteria, fungi and a few protozoan species, and it seems to be absent in humans [5]. The enzymes participating in the galactan build-up could thus be considered as potential targets for new antitubercular drug developments [6]. Mycobacterial galactan is synthesized by two bifunctional galactofuranosyltransferases, GlfT1 and GlfT2 (Supporting Information File 1, Figure S1). The former one initiates the galactan biosynthesis by addition of the first two Gal $f$ residues to decaprenyl-P-P-GlcNAc-Rha, (glycolipid 2, GL2), which serves as a lipid carrier for arabinogalactan polymerization [7,8]. The latter enzyme, GlfT2, extends the product of GlfT1-catalyzed reaction, decaprenyl-PP-GlcNAc-Rha-Gal $f_{2}$ (glycolipid 4, GL4), producing the lipidlinked galactan polymer [8]. Both enzymes require an activated sugar donor uridine diphosphate (UDP)-Galf, which is synthesized from UDP-galactopyranose (UDP-Galp) by the enzyme UDP-Gal $p$ mutase [9] (Supporting Information File 1, Figure $\mathrm{S} 1)$

The recently published GlfT2 X-ray structure with a UDP donor part [10] was used in the reaction mechanism studies using computational chemistry methods. The probable reaction mechanisms were studied by hybrid DFT QM/MM molecular dynamics simulations [11] where the possible transition state (TS) structures were localized. The observation of the possible TS structure opens the opportunities for the in silico based design of possible GlfT2 inhibitors that mimic the TS structure.

The galactofuranosyltransferase GlfT2 is a bisubstrate enzyme with a single catalytic domain and its catalytic reaction transition state shares some structural similarities with the previously modeled $N$-acetylglucosaminyltransferase I (GnT-I) reaction transition state [11]. Previously, we have designed 2-thiohexofuranoside skeletons bearing a phosphate group in position 1 by molecular modeling as potential transition state inhibitors of human glycosyltransferase I (GnT-I) [12], the bisubstrate enzyme requiring a metal co-factor for the proper synthesis of $N$-glycans [13]. Subsequently, pioneer structures based on D-fructofuranose [14], D-tagatofuranose or D-psicofuranose $[15,16]$ have been prepared, but their inhibitory activity could not have been tested due to their low stability under standard conditions [16]. Further investigations on their more stable analogs resulted in the synthesis of stable $1-O$-phoshono- $\beta$-Dpsicofuranosyl sulfone, which was prepared by a simultaneous phosphorylation and oxidation of ethyl 2-thio- $\beta$-D-psicofuranoside with dibenzyl $N, N$-dimethylphosphoramidite catalyzed by $1 H$-tetrazole and followed by treatment with an excess of 3-chloroperbenzoic acid [16]. Fortunately, the molecular modeling studies did not bring any significant contention about the negative influence of the $\mathrm{SO}_{2}$ group in the target molecule on the standard molecular docking parameters [16]. Based on this fact, a new generation of stable possible inhibitors of GnT-I, comprising structures derived from the D-fructofuranose skeleton bearing an $\mathrm{SO}_{2}$ group and sulfated at the position $\mathrm{C}-1$ were prepared [17]. However, these compounds did not show any significant inhibitory activity [17]. Therefore, we decided to prepare structures originally suggested by molecular modeling having the 1-O-phosphate group stabilized by anomeric sulfones on the D-fructofuranose and D-tagatofuranose skeleton (1-3, Figure 1). Similarities in the TS structures of GnT-I and GlfT2 prompted us to examine these molecules against GlfT2, a possible target for the development of the drugs against tuberculosis. Despite that the studied structures do not contain the galacto configuration on the furanose ring, the studied compounds mimic the TS structure of the GlfT2 catalytic reaction. The TS structure mimetics are stable compounds designed to mimic the unstable TS complex structure and also mimic its partial charges and charge distribution. Herein, the molecular docking, synthesis and inhibitory activity of D-fructofuranosyl and D-tagatofuranosyl sulfones 1-3 against GlfT2 are discussed. Moreover, we extended the scope of the simultaneous phosphorylation and oxidation to 2-thio-D-fructo- and 2-thio-Dtagatofuranosides as the key step in the synthesis of target structures.<smiles>[R]O[C@]1(COP(=O)(O)O)O[C@H](CO)[C@@H](O)[C@H]1O</smiles>

$1 \alpha$<smiles>[R]O[C@]1(COP(=O)(O)O)O[C@H](CO)[C@@H](O)[C@H]1O</smiles>

2<smiles>[R]O[C@]1(COP(=O)(O)O)O[C@H](CO)[C@@H](O)[C@H]1O</smiles>

$1 \beta$
Figure 1: Target D-fructofuranosyl and D-tagatofuranosyl sulfones 1-3.

\section{Results and Discussion Docking study}

In the presented study, the compounds based on the fructofuranose and tagatofuranose derivatives (Figure 1) were docked into the GlfT2 structure. The proposed structures nicely follow the probable TS structure of the GlfT2 catalytic reaction as is shown in Supporting Information File 1, Figure S2. The available GlfT2 X-ray structure contains only the UDP part of the native UDP-Gal $f$ donor substrate (PDB ID: 4FIY). The struc- 
ture of the UDP-Gal $f$ was docked into the GlfT2 structure to obtain the docking score of the native substrate. The observed UDP-Gal $f$ docking score serves as a reference for the studied compounds. The obtained UDP-Gal $f$ docking pose showed almost the same binding mode of the UDP moiety as UDP present in the X-ray structure (Supporting Information File 1, Figure S3). A small movement was observed only for the diphosphate part due to the proper accommodation of the Galf moiety within the GlfT2 binding pocket. This suggested that the UDP-Gal $f$ docked binding pose was reliable and could be used as a reference for the docking of the studied structures. All fructofuranose and tagatofuranose derivatives were docked into the GlfT2 structure obtained by QM/MM molecular dynamics simulations, which representes the structure close to the transition state structure of the GlfT2 catalytic reaction. The best ten docking poses of each docked molecule were saved for further analyses.

The docking predicted one or two main binding modes for each docked molecule. The most populated binding mode also contained the binding pose with the lowest docking score (for which the highest affinity was predicted). Only the binding modes with the lowest docking score will be discussed below. The observed binding modes of the docked molecules revealed some common interaction patterns. Interactions of the $\mathrm{PO}_{4}$ group with a metal ion and arginine R171 were observed in almost all docking poses and in some cases the $\mathrm{C} 2$ hydroxy group also interacted with a metal ion. The C5 hydroxy group very often interacts with the catalytic base aspartate D372 side chain. Moreover, in the poses where this interaction has been found, the C5 hydroxy group creates a hydrogen bond with the ammonium group of the lysine K369 residue. In many docking poses the interaction of the $\mathrm{C} 3$ hydroxy group with the aspartate D256 has also been seen. The $\mathrm{SO}_{2}$ unit attached to alkyl/ aryl substituents have been found in two main binding modes. In one binding mode the alkyl/aryl part is bound towards the uridine binding pocket of the UDP-Galf. The second binding mode was found in the place where the acyclic tail of the native Gal $f$ is bound. The binding poses with the highest docking score of the four compounds with the highest predicted affinity are shown in Figure 2. The highest binding affinity was predicted for compounds $1 \mathbf{b} \boldsymbol{\alpha}, \mathbf{2 c}, \mathbf{3 c}$ and $\mathbf{1 c \beta}$. It can be seen that the com-

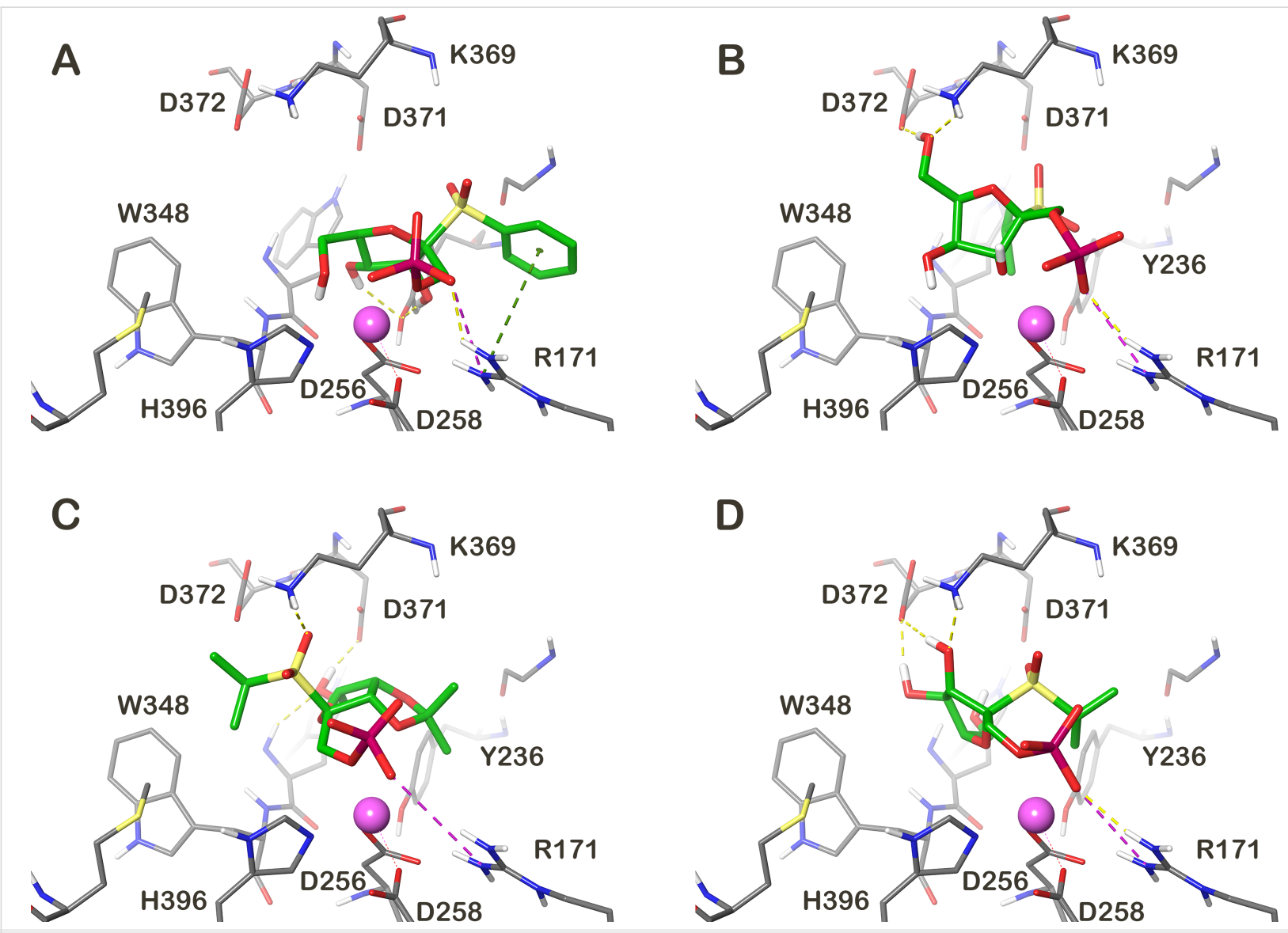

Figure 2: Molecular representation of the best binding poses of the four compounds with the predicted highest affinity. (A) 1 bo, (B) $2 c$, (C) $3 \mathbf{c}$ and (D) $1 \mathrm{c} \beta$. The molecule-GlfT2 interactions are depicted as dashed lines (yellow - hydrogen bonds, magenta - salt bridge, green - cation/ $\pi$ interaction). The $\mathrm{Mg}^{2+}$ ion is shown as a purple sphere. 
pounds $2 \mathbf{c}, 3 \mathbf{c}$ and $1 \mathbf{c} \beta$ share the common binding interactions described above. However, the $\mathbf{1} \mathbf{b} \boldsymbol{\alpha}$ binding mode slightly differed from the modes of the other compounds. In this case the $\mathrm{PO}_{4}$ and hydroxy group on $\mathrm{C} 5$ interacted with a metal ion and the hydroxy groups on $\mathrm{C} 2$ and $\mathrm{C} 3$ created the hydrogen bond with the tyrosine Y236 hydroxy group and the phenyl ring created a cation $-\pi$ stacking interaction with the arginine R171 side chain (Figure 2).

The observed theoretical binding energy in $\mathrm{kcal} / \mathrm{mol}$ represented by the docking scores and the predicted binding affinities for the UDP-Gal $f$, fructofuranose, and tagatofuranose compounds are listed in Table 1.

\begin{tabular}{|c|c|c|}
\hline Compound & Docking score $[\mathrm{kcal} / \mathrm{mol}]$ & Predicted $K_{\mathrm{i}}[\mu \mathrm{M}]$ \\
\hline UDP-Galf & -9.192 & $0.333^{a}$ \\
\hline $1 \mathrm{a} \alpha$ & -7.505 & 5.148 \\
\hline $1 b \alpha$ & -8.678 & 0.767 \\
\hline $1 c \alpha$ & -7.952 & 2.492 \\
\hline $1 c \beta$ & -8.648 & 0.805 \\
\hline $2 a$ & -7.701 & 3.745 \\
\hline $2 b$ & -8.388 & 1.228 \\
\hline 2c & -8.389 & 1.226 \\
\hline $3 a$ & -6.382 & 31.839 \\
\hline $3 b$ & -6.900 & 13.739 \\
\hline $3 c$ & -8.549 & 0.946 \\
\hline
\end{tabular}

aExperiment: 250 or $380 \mu \mathrm{M}$ at $37^{\circ} \mathrm{C}[10,18,19]$.

Firstly, the UDP-Gal $f$ native donor substrate was docked into the GlfT2 crystal structure to observe the reference docking score and to predict the $K_{\mathrm{i}}$ value for the native donor substrate. The predicted $K_{\mathrm{i}}$ value of the UDP-Gal $f$ is $0.333 \mu \mathrm{M}$, however, the experimentally observed $K_{\mathrm{m}}$ values of the UDP-Galf binding were 250 or $380 \mu \mathrm{M}$ at $37{ }^{\circ} \mathrm{C}[10,18,19]$. All the predicted values were calculated for this temperature. This observation suggested that the calculated docking score overestimated the predicted binding affinities by three orders of magnitude. Unfortunately, the experimental $K_{\mathrm{m}}$ or $K_{\mathrm{i}}$ values of the structures similar to the studied compounds were not available and therefore we were not able to create a more precise linear regression model for the binding affinity prediction. For this reason, we could use only a coarse correction for the calculated $K_{\mathrm{i}}$ values and the experimental $K_{\mathrm{i}}$ values can be expected in the $\mathrm{mM}$ and sub-mM range rather than in the $\mu \mathrm{M}$ and sub- $\mu \mathrm{M}$ range. However, the obtained predicted $K_{\mathrm{i}}$ values were reliable for the comparison of the fructofuranose and tagatofuranose compounds binding affinities with the UDP-Gal $f$ binding affinity. Moreover, the $K_{\mathrm{i}}$ values gave a more realistic image about the affinity differences between the compounds than only the predicted binding energies. The observed docking score of the studied compounds ranged from -6.4 to $-8.7 \mathrm{kcal} / \mathrm{mol}$. All these values were higher than the observed docking score for the UDP-Galf. This means that the docking predicted a lower affinity for the studied compound than for the native substrate. Recalculation of the observed docking scores to the $K_{\mathrm{i}}$ values showed that the predicted affinity of the studied compounds ranged from $0.7 \mu \mathrm{M}$ to $32 \mu \mathrm{M}$. In case of the best four compounds with the highest affinity $(\mathbf{1 b} \boldsymbol{\alpha}, \mathbf{2 c}, \mathbf{3 c}, \mathbf{1 c \beta})$ the $K_{\mathrm{i}}$ values ranged up to $1.2 \mu \mathrm{M}$. The predicted affinity of these compounds was just three to four times lower than the predicted affinity for the UDP-Galf. Such observation is very promising, due to the fact that the studied molecules were smaller, they did not show as many interactions as the native donor substrate and created only one strong interaction with the metal ion cofactor. So further modification of these four molecules can lead to the compounds with similar or higher affinities to the GlfT2 than UDP-Galf.

\section{Chemistry}

Within the structure of target compounds $\mathbf{1 - 3}$, the carbohydrate skeletons resembled the donor substrate: various $\mathrm{RSO}_{2}$ aglycons mimic an approaching acceptor substrate while the 1-Ophosphono moiety represents the leaving UDP [20].

The synthesis of target compounds 1-3 consisted of two different strategies. The first one was applied to a series of D-fructofuranose derivatives $\mathbf{1}$ and started from the four known alcohols $\mathbf{4} \boldsymbol{\alpha}, \mathbf{5} \boldsymbol{\alpha}, \mathbf{5 \beta}$ and $\mathbf{6} \boldsymbol{\alpha}$ [17]. Initial treatment of these alcohols with commercially available dibenzyl $N, N$-dimethylphosphoramidite as phosphorylating agent catalyzed by $1 H$-tetrazole and followed by direct oxidation with an excess of 3-chloroperbenzoic acid ( $m$-CPBA, 12 equiv) led to the simultaneous phosphorylation of the hydroxy group and to the oxidation of the sulfide to give 1-O-dibenzyloxyphosphoryl-D-fructofuranosyl sulfones $7 \boldsymbol{\alpha}, \mathbf{8 \alpha}, \mathbf{8 \beta}$ and $\mathbf{9 \alpha}$ in excellent yields (Scheme 1). Final removal of benzyl protecting groups by catalytic hydrogenation provided target 1- $O$-phosphono-D-fructofuranosyl sulfones $\mathbf{1 a} \alpha$, $\mathbf{1 b} \boldsymbol{\alpha}, \mathbf{1 b} \boldsymbol{\beta}$ and $\mathbf{1 c} \boldsymbol{\alpha}$ as white powders after freeze drying.

Based on the molecular docking results, the series of D-tagatofuranose compounds can be divided into two groups. The first group represented the more flexible structures 2 with free hydroxy groups in positions $\mathrm{C} 3$ and $\mathrm{C} 4$, while the second group of target compounds $\mathbf{3}$ has hydroxy groups on $\mathrm{C} 3$ and $\mathrm{C} 4$ protected as acetonides which made their structure more rigid. The synthesis started from the well-known diacetonide 10 [17]. Pivaloylation of the free hydroxy group at C-6 of $\mathbf{1 0}$ smoothly gave $\mathbf{1 1}$ in good yield. Likewise, 6-O-benzyl derivative $\mathbf{1 2}$ was 


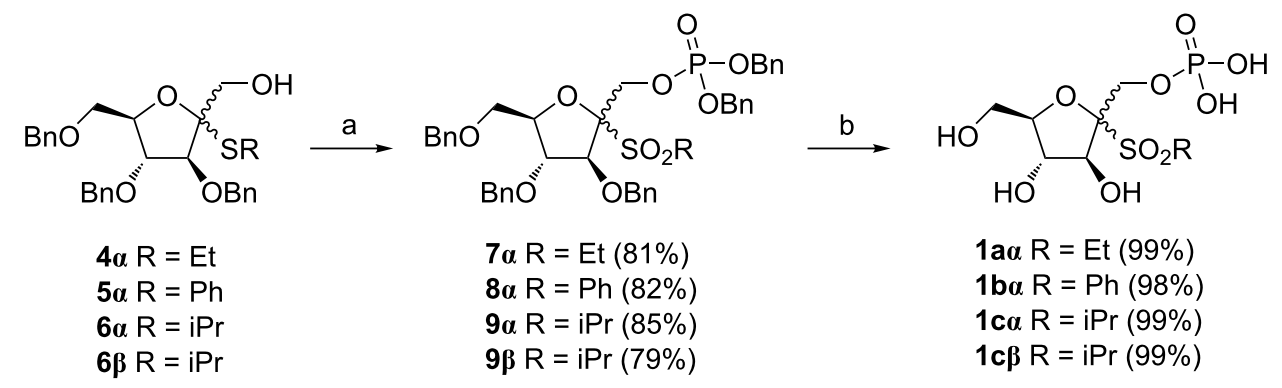

Scheme 1: Reagents and conditions: a) 1. $(\mathrm{BnO})_{2} \mathrm{P}-\mathrm{NMe}_{2}, 1 \mathrm{H}$-tetrazole, $0{ }^{\circ} \mathrm{C} \rightarrow \mathrm{rt}, 1 \mathrm{~h}, 2 . \mathrm{m}-\mathrm{CPBA}, 0{ }^{\circ} \mathrm{C} \rightarrow \mathrm{rt}, 1.5-2 \mathrm{~h}$; b) $\mathrm{H}_{2}, 10 \% \mathrm{Pd} / \mathrm{C}, \mathrm{MeOH}, \mathrm{rt}$, 3-4 h.

prepared to reduce reaction steps and to ensure a clean progress of the benzyl protecting group removal by catalytic hydrogenation (Scheme 2).

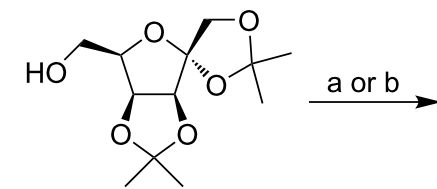

10

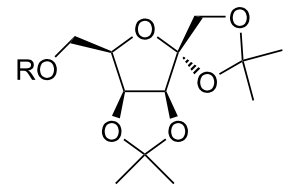

$11 \mathrm{R}=\operatorname{Piv}(85 \%)$

$12 \mathrm{R}=\mathrm{Bn}(91 \%)$
Scheme 2: Reagents and conditions: a) PivCl, pyridine, $\mathrm{CH}_{2} \mathrm{Cl}_{2}$, rt, overnight; b) $\mathrm{BnBr}, \mathrm{NaOH}, \mathrm{TBAB}, \mathrm{THF}$, reflux, $3 \mathrm{~h}$.
The direct thioglycosylation of $\mathbf{1 1}$ with ethanethiol in the presence of $\mathrm{BF}_{3} \cdot \mathrm{OEt}_{2}$ afforded 2-thio-D-tagatofuranoside $\mathbf{1 3}$ in satisfactory yield (Scheme 3 ). In the course of the thioglycosylation, only the $\alpha$-anomer of $\mathbf{1 3}$ was detected and isolated as the product. In general, the formation of $\alpha$-anomers during the thioglycosylation of di- $O$-isopropylidene-D-tagatofuranoses $\mathbf{1 1}$ and $\mathbf{1 2}$ was controlled by the approach of a thiol from exo-face of the bicyclic skeleton. Subsequent simultaneous phosphorylation and oxidation of ethyl 2-thio-D-tagatofuranoside 13 under identical conditions as used for the fructofuranose pathway provided 1-O-dibenzyloxyphosphoryl-D-tagatofuranosyl sulfone $\mathbf{1 4}$ (Scheme 3). Removal of the pivaloyl protecting group in derivative $\mathbf{1 4}$ led to alcohol $\mathbf{1 5}$ as the common intermediate for the synthesis of target structures $\mathbf{2 a}$ and 3a. The fully deprotected<smiles>CC1(C)OCC2(COC(C)(C)C(CON)O2)O1</smiles>

11<smiles>CCOC1(COP(=O)(O)O)O[C@H](CO)C(O)C1O</smiles>

2a $(98 \%)$<smiles>CC[C@]1(CO)O[C@H](CO[NH+])C[C@H]1OC</smiles>

$13(59 \%)$<smiles>CCO[C@@]1(COP(=O)(OCc2ccccc2)OCc2ccccc2)O[C@H](CO)C(O)C1O</smiles><smiles>CCO[C@]1(COP(OCc2ccccc2)OCc2ccccc2)O[C@H](CO)[C@@H]2OC(C)(C)O[C@H]21</smiles><smiles>CCO[C@]1(COP(=O)(O)O)O[C@@H](CO)[C@H]2OC(C)(C)O[C@@H]21</smiles>

3a $(98 \%)$ 
target compound 2a was obtained in good yield by acidic hydrolysis of the acetonide protecting group with $3 \mathrm{M} \mathrm{HCl}$ in THF followed by catalytic hydrogenation of $\mathbf{1 6}$. On the other hand, direct catalytic hydrogenation of $\mathbf{1 5}$ furnished target structure 3a with the hydroxy groups protected on $\mathrm{C} 3$ and $\mathrm{C} 4$ as an acetonide.

Direct thioglycosylation of diacetonide 12 with corresponding thiols (PhSH, iPrSH) led to expected 2-thio-D-tagatofuranosides 17a and 17b in $44 \%$ and $54 \%$ yield, respectively. Moderate yields of 2-thio-D-tagatofuranosides $\mathbf{1 7}$ can be explained by cleavage of the benzyl protecting group [21] as well as further side reactions (Scheme 4).

In order to increase the yield of 2-thio-D-tagatofuranosides 17, compound $\mathbf{1 2}$ was converted to the more reactive diacetate $\mathbf{1 8}$ under acetolysis conditions $\left(\mathrm{Ac}_{2} \mathrm{O} / \mathrm{BF}_{3} \cdot \mathrm{OEt}_{2}\right)$ [22]. However, besides the expected diacetate 18, 1,2,6-tri- $O$-acetate 19 was observed and isolated as a byproduct (Scheme 4 ). The cleavage of the $O$-benzyl ethers followed by acetylation of the liberated hydroxy groups under acidic conditions was described previously, however, concentrated $\mathrm{H}_{2} \mathrm{SO}_{4}$ is usually employed as a promotor in acetic anhydride [23]. Although thioglycosylation of diacetate 18 with $\mathrm{PhSH}$ provided 2-thio-D-tagatofuranoside 20 in $72 \%$ yield, the overall synthesis of $\mathbf{1 7}$ a would contain two more reaction steps and, thus, be less effective. As the yields of 2-thio-D-tagatofuranosides $\mathbf{1 7}$ were comparable to the yield of 2-thio-D-tagatofuranoside $\mathbf{1 3}$ obtained by thioglycosylation of 11, derivative $\mathbf{1 2}$ proved to be a more suitable substrate for the synthesis of target compounds $\mathbf{2}$ and $\mathbf{3}$ due to the possibility of simultaneous deprotection of the benzyl protecting groups in later stages of the synthesis. This advantage makes the overall synthesis of the target molecules one reaction step shorter in comparison with the synthesis starting from pivalate $\mathbf{1 1}$
(Scheme 3). With alcohols $\mathbf{1 7}$ in hand, the synthesis continued with their simultaneous phosphorylation and oxidation under the above-mentioned conditions to give 1- $O$-dibenzyloxyphosphoryl-D-tagatofuranosyl sulfones 21 (Scheme 5). Next, catalytic hydrogenation of $\mathbf{2 1}$ afforded the final acetonides $\mathbf{3 b}$ and $\mathbf{3 c}$ in excellent yields. The fully deprotected target structures $\mathbf{2 b}$ and $2 \mathbf{c}$ were obtained by acetonide hydrolysis under acidic conditions followed by the final catalytic hydrogenation of the benzyl protecting groups in derivatives $\mathbf{2 2}$.

\section{Evaluation of the effects of the target compounds on the synthesis of lipid-linked galactan precursors}

The availability of a series of compounds with different predicted affinities towards GlfT2 according to the docking studies (Table 1) encouraged us to evaluate them experimentally. The compounds were tested in an assay using an enzymatically active fraction of cell envelope from Mycobacterium smegmatis mc ${ }^{2} 155$ and UDP- $\left[{ }^{14} \mathrm{C}\right] \mathrm{Gal} p$ as a tracer of the build-up of lipid-linked galactan precursors. The crude enzymes used in the assay allow for in situ synthesis of the acceptor for galactan polymerization, decaprenyl-P-P-GlcNAc-Rha (GL2), from endogenous decaprenyl phosphate and sugar nucleotides UDPGlcNAc and TDP-Rha supplied in the reaction mixture. Conversion of UDP- $\left[{ }^{14} \mathrm{C}\right] \mathrm{Gal} p$ to UDP- $\left[{ }^{14} \mathrm{C}\right] \mathrm{Gal} f$, which is required by mycobacterial galactofuranosyl transferases, was enabled by trace amounts of the cytosolic UDP-Galp mutase present in the prepared enzyme fraction. Consequently, this assay monitored not only GlfT2, but also activities of other enzymes employed in the synthesis of its acceptor substrate, decaprenyl-P-P-GlcNAc-Rha-Galf $f_{2}$ (GL4). Based on the previous experimental data, which established $K_{\mathrm{m}}$ values for GlfT2 250 or $380 \mu \mathrm{M}$ at $37{ }^{\circ} \mathrm{C}[10,18,19]$, we tested the whole set of target compounds at a concentration of $500 \mu \mathrm{M}$. TLC

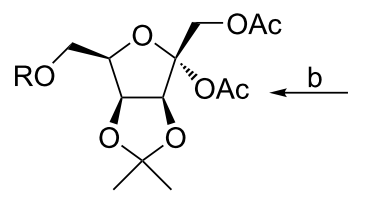

$18 \mathrm{R}=\mathrm{Bn}(59 \%)$

$19 \mathrm{R}=\mathrm{Ac}(28 \%)$<smiles>CC1(C)OCC2(OC(COc3ccccc3)C3OC(C)(C)C3O2)O1</smiles>

12

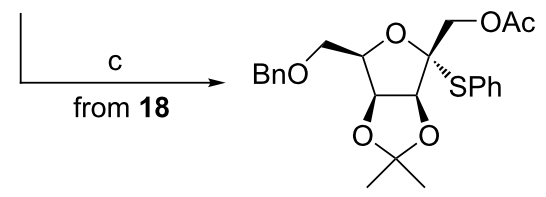

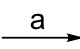

$\mathrm{BnO}$<smiles>[R]C1(CO)OC(CO)C2OC(C)(C)OC21</smiles>

$17 \mathrm{a} \mathrm{R}=\mathrm{Ph}(44 \%)$ $17 b \mathrm{R}=\mathrm{i} \operatorname{Pr}(54 \%)$ 


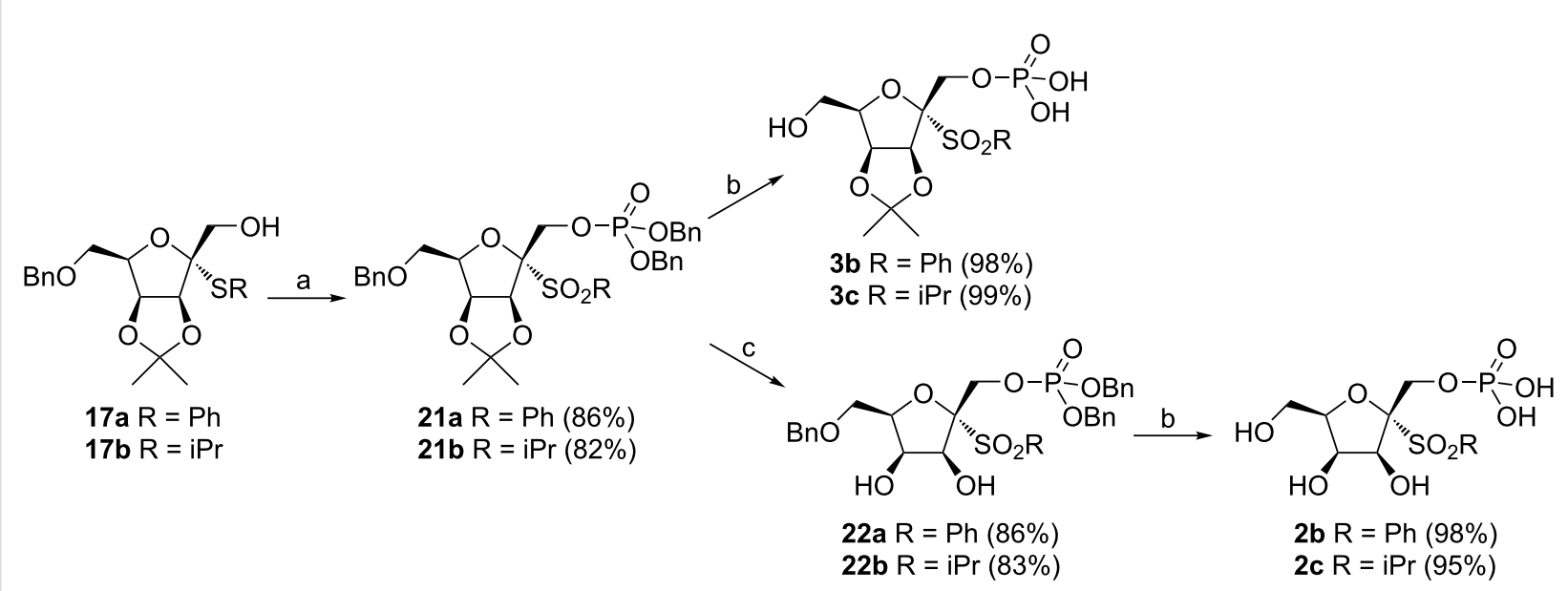

Scheme 5: Reagents and conditions: a) 1 . (BnO) ${ }_{2} \mathrm{P}-\mathrm{NMe}_{2}, 1 \mathrm{H}$-tetrazole, $0{ }^{\circ} \mathrm{C} \rightarrow \mathrm{rt}, 1 \mathrm{~h}, 2 . \mathrm{m}-\mathrm{CPBA}, 0{ }^{\circ} \mathrm{C} \rightarrow \mathrm{rt}, 1.5-2 \mathrm{~h}$; b) $\mathrm{H}_{2}, 10 \% \mathrm{Pd} / \mathrm{C}, \mathrm{MeOH}, \mathrm{rt}$, 3-4 h; c) $3 \mathrm{M} \mathrm{HCl}$, THF, $40^{\circ} \mathrm{C}, 8 \mathrm{~h}$.

analysis of the lower galactan precursors, decaprenyl-P-PGlcNAc-Rha-Galf $f_{1-3}$ (GL3-5) shows that under our experimental conditions none of the enzymes involved in the synthesis of lipid-linked galactan, including the galactofuranosyl transferases GlfT1 (produces GL3 and GL4) and GlfT2 (produces GL5), were affected (Figure 3).

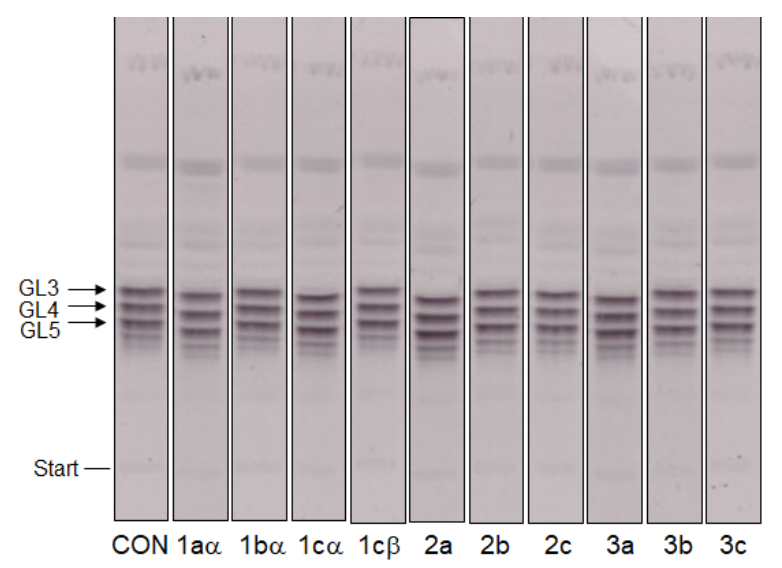

Figure 3: TLC analysis of the effects of the target compounds at $500 \mu \mathrm{M}$ on the production of lower lipid-linked galactan precursors. CON, control; GL3-5, glycolipids 3-5. GL3 and GL4 are products of GlfT1, GL5 is produced by GlfT2.

Despite the predicted low docking scores for the compounds $\mathbf{1 b \alpha}, \mathbf{2 c}, \mathbf{3 c}$ and $\mathbf{1 c \beta}$, the quantification of the incorporation of the radioactive label to the more polymerized lipid-linked galactan precursors did not reveal inhibitory effects (Supporting Information File 1, Table S1). Nevertheless, our recent summary of the efforts towards identification of GlfT1 and GlfT2 inhibitors revealed that most compounds were reported to have effects on these enzymes at low mM concentrations (up to
$8 \mathrm{mM}$ ) [6]. These molecules were designed as substrate mimics or transition state analogs and their $\mathrm{IC}_{50}$ values, ranging between $0.332-3.85 \mathrm{mM}$ were established by a spectrophotometric assay with a purified recombinant GlfT2 enzyme, UDPGal $f$ as a donor substrate and analogs of the acceptor substrate [24-30]. The best reported $\mathrm{IC}_{50}$ value $(0.180 \mathrm{mM})$ for a putative GlfT2 inhibitor was obtained for a fluorinated exo-glycal analogue of UDP-Gal $f$ in a radiometric assay with a glycolipid acceptor substrate and crude mycobacterial enzymes [31]. Therefore, we decided to examine compounds $\mathbf{1 b} \boldsymbol{\alpha}$ and $\mathbf{3 a}$, representing the best and the worst inhibitors, respectively, according to the docking study, in the range of 1-10 mM. Interestingly, while compound $\mathbf{1 b \boldsymbol { \alpha }}$ showed a dose-dependent inhibitory effect in this experiment, compound 3a did not (Table 2). Although the crude system that we used in the enzymology experiments precludes precise kinetic characterization of the studied inhibitors on the target enzyme, GlfT2, it does have some advantages compared to the spectrophotometric GlfT2 assay [19]. Firstly, in the crude assay GlfT2 uses its natural acceptor, GL4, which could affect its activity and thus the outcome of the inhibition studies. Secondly, it allows to evaluate inhibition of the enzymes involved in GL4 production (WecA, WbbL, UGM, GlfT1; Supporting Information File 1, Figure S1) [6] by the tested compounds, which could indicate the unspecific effects. These cannot be precluded, especially if relatively high concentrations of the studied molecules are required for achieving substantial enzyme inhibition, which is the case for the reported GlfT2 inhibitors [6,24]. In our experiment TLC examination of the lower galactan precursors (GL3-5) points to subtle changes in their relative amounts in the presence of $\mathbf{1 b} \boldsymbol{\alpha}$ in the reaction mixture (Figure 4). In the control reaction, the major radiolabeled glycolipid species are GL4, the product of GlfT1 and GL5, the product of GlfT2. In the pres- 
Table 2: Evaluation of the effects of compounds $\mathbf{1 b} \boldsymbol{\alpha}$ and $\mathbf{3 a}$ on the synthesis of the lipid-linked galactan polymera

\begin{tabular}{|c|c|c|c|c|}
\hline Compound & Set1 (dpm) & Set2 (dpm) & Average & $\%$ of inhibition \\
\hline control & 11,449 & 9,587 & 10,518 & 0 \\
\hline $1 \mathrm{mM} \mathbf{1} \mathbf{b} \boldsymbol{\alpha}$ & 10,041 & 11,384 & 10,712 & -2 \\
\hline $2 \mathrm{mM} \mathbf{1 b} \alpha$ & 9,912 & 8,937 & 9,425 & 10 \\
\hline $5 \mathrm{mM} \mathbf{1 b} \alpha$ & 7,124 & 6,354 & 6,739 & 36 \\
\hline $10 \mathrm{mM} \mathbf{1 b} \boldsymbol{\alpha}$ & 3,051 & 2,887 & 2,969 & 72 \\
\hline $1 \mathrm{mM} 3 \mathbf{a}$ & 8,602 & 8,638 & 8,620 & 18 \\
\hline $2 \mathrm{mM} 3 a$ & 8,580 & 6,498 & 7,539 & 28 \\
\hline 5 mM 3a & 6,054 & 6,029 & 6,041 & 43 \\
\hline $10 \mathrm{mM} 3 \mathbf{a}$ & 7,631 & 7,063 & 7,347 & 30 \\
\hline
\end{tabular}

The values in the table represent total incorporation of radioactive galactose from UDP-[ $\left.{ }^{14} \mathrm{C}\right]$-Gal into the lipid-linked galactan polymer extracted by the solvents TT3 and E-soak (see Experimental part in Supporting Information File 1) in duplicate sets. The experiments were performed with $250 \mu \mathrm{g}$ of the cell envelope protein in the reaction mixtures.

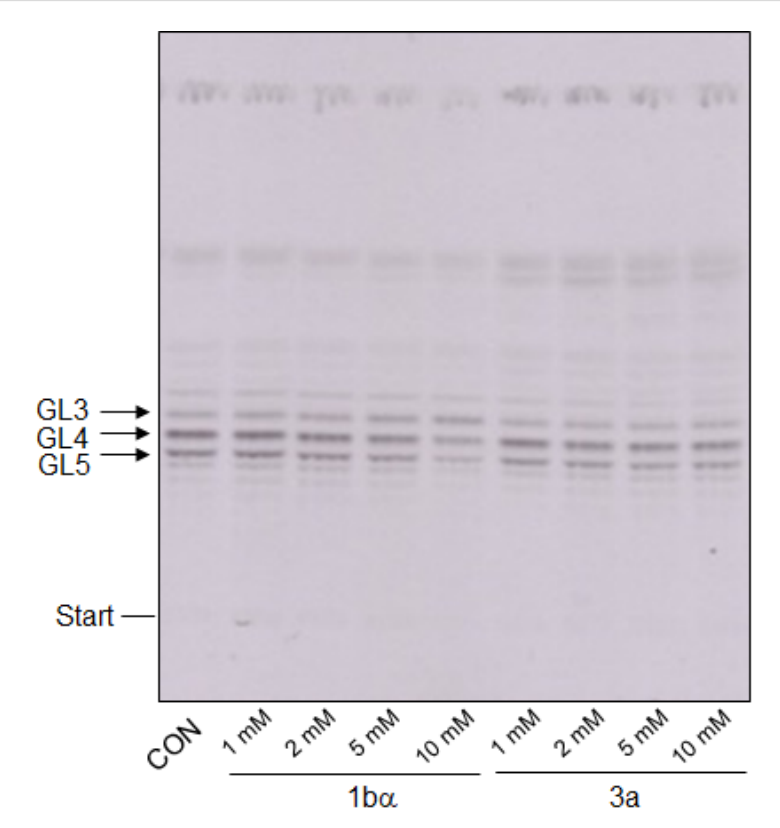

Figure 4: TLC analysis of the dose effects of the compounds $\mathbf{1 b} \boldsymbol{\alpha}$ and 3a on production of lower lipid-linked galactan precursors. CON, control; GL3-GL5, glycolipids 3-5. GL3 and GL4 are the products of GlfT1, GL5 is produced by GlfT2.

ence of $10 \mathrm{mM} \mathbf{1 b \boldsymbol { \alpha }}$ the predominant bands are GL3 and GL4, the products of GlfT1, which could point to a GlfT2 inhibition.

\section{Conclusion}

In summary, a small library of D-fructofuranosyl and D-tagatofuranosyl sulfones 1-3 was synthesized. We performed docking studies of these compounds into the active site of GlfT2 by computational chemistry methods. Although the docking study showed good binding affinities of the prepared compounds towards the GlfT2 active site, their biological evaluation revealed a very poor effect on the synthesis of lipid-linked galactan. However, the experiments evaluating the dose effects of the predicted best (1ba) and the worst (3a) inhibitor on the mycobacterial galactan synthesis indicated the possibility of GlfT2 inhibition by $\mathbf{1 b} \boldsymbol{\alpha}$ at the highest tested concentration $(10 \mathrm{mM})$. However, it is clear that given the high concentration of this compound required to achieve inhibitory effects on the galactan synthesis, this approach requires further optimization. Indeed, our pilot docking study was performed with compounds initially targeted at the transition state of GnT-I. Moreover, presented structures do not include the uridine mimicking part which can increase the binding affinity significantly. Attaching of this part is a topic of further synthesis and secondgeneration compound library preparation. We believe that our further efforts, both in synthetic and computational fields, will point to the potential of the in silico methods for the design of new GlfT2 inhibitors.

\section{Supporting Information}

The Supporting Information provides the biochemical pathway for the biosynthesis of mycobacterial galactan, superimposition of docked structures and evaluation of the effects of the target compounds on the synthesis of the lipid-linked galactan polymer. Complete experimental procedures, spectral characterization of all prepared compounds and copies of their ${ }^{1} \mathrm{H}$ NMR and ${ }^{13} \mathrm{C}$ NMR spectra are also provided.

\section{Supporting Information File 1}

Experimental and analytical data.

[https://www.beilstein-journals.org/bjoc/content/ supplementary/1860-5397-16-152-S1.pdf] 


\section{Funding}

The presented work was supported by the project VEGA 2/ 0024/16 and by the Slovak Research and Development Agency (APVV-15-0515). The research has also been financed by program SASPRO (ArIDARuM, 0005/01/02) - co-funded by the People Programme (Marie Curie Actions 7FP, grant agreement REA no. 609427) and co-financed by the Slovak Academy of Sciences (S.K.).

\section{ORCID ${ }^{\circledR}$ iDs}

Marek Baráth - https://orcid.org/0000-0003-2200-9623

Stanislav Kozmon - https://orcid.org/0000-0002-0946-3453

Katarína Mikušová - https://orcid.org/0000-0002-0100-4877

Maroš Bella - https://orcid.org/0000-0001-6556-1579

\section{References}

1. Global TB Report 2019; WHO: Geneva, Switzerland, 2019. https://apps.who.int/iris/bitstream/handle/10665/329368/978924156571 4-eng.pdf?ua=1 (accessed Feb 13, 2020).

2. Tiberi, S.; du Plessis, N.; Walzl, G.; Vjecha, M. J.; Rao, M.; Ntoumi, F.; Mfinanga, S.; Kapata, N.; Mwaba, P.; McHugh, T. D.; Ippolito, G.; Migliori, G. B.; Maeurer, M. J.; Zumla, A. Lancet Infect. Dis. 2018, 18, e183-e198. doi:10.1016/s1473-3099(18)30110-5

3. Daffé, M.; Marrakchi, H. Microbiol. Spectrum. 2019, 7, No. 4. doi:10.1128/microbiolspec.gpp3-0027-2018

4. Bhamidi, S.; Scherman, M. S.; Jones, V.; Crick, D. C.; Belisle, J. T.; Brennan, P. J.; McNeil, M. R. J. Biol. Chem. 2011, 286, 23168-23177. doi:10.1074/jbc.m110.210534

5. Richards, M. R.; Lowary, T. L. ChemBioChem 2009, 10, 1920-1938. doi:10.1002/cbic.200900208

6. Konyariková, Z.; Savková, K.; Kozmon, S.; Mikušová, K. Antibiotics (Basel, Switz.) 2020, 9, No. 20. doi:10.3390/antibiotics 9010020

7. Mikušová, K.; Mikuš, M.; Besra, G. S.; Hancock, I.; Brennan, P. J. J. Biol. Chem. 1996, 271, 7820-7828. doi:10.1074/jbc.271.13.7820

8. Beláňová, M.; Dianišková, P.; Brennan, P. J.; Completo, G. C.; Rose, N. L.; Lowary, T. L.; Mikušová, K. J. Bacteriol. 2008, 190, 1141-1145. doi:10.1128/jb.01326-07

9. Weston, A.; Stern, R. J.; Lee, R. E.; Nassau, P. M.; Monsey, D.; Martin, S. L.; Scherman, M. S.; Besra, G. S.; Duncan, K.; McNeil, M. R. Tubercle Lung Dis. 1998, 78, 123-131. doi:10.1016/s0962-8479(98)80005-1

10. Wheatley, R. W.; Zheng, R. B.; Richards, M. R.; Lowary, T. L.; Ng, K. K. S. J. Biol. Chem. 2012, 287, 28132-28143. doi:10.1074/jbc.m112.347484

11. Janoš, P.; Kozmon, S.; Tvaroška, I.; Koča, J. Chem. - Eur. J. 2018, 24, 7051-7059. doi:10.1002/chem.201800558

12. Raab, M.; Kozmon, S.; Tvaroška, I. Carbohydr. Res. 2005, 340, 1051-1057. doi:10.1016/j.carres.2005.01.041

13. Varki, A.; Cummings, R. D.; Esko, J. D.; Freeze, H. H.; Stanley, P.; Bertozzi, C. R.; Hart, G. W.; Etzler, M. E. Essentials of Glycobiology, 2nd ed.; Cold Spring Harbor Laboratory Press: Cold Spring Harbor, NY, U.S.A., 2009

14. Baráth, M.; Koóš, M.; Tvaroška, I.; Hirsch, J. Chem. Pap. 2015, 69, 339-347. doi:10.1515/chempap-2015-0017

15. Baráth, M.; Lin, C.-H.; Tvaroška, I.; Hirsch, J. Chem. Pap. 2015, 69, 348-357. doi:10.1515/chempap-2015-0063
16. Bella, M.; Yan, S.; Šesták, S.; Kozmon, S.; Lin, C.-H.; Mucha, J.; Koóš, M. Eur. J. Org. Chem. 2017, 6179-6191. doi:10.1002/ejoc.201701102

17. Jakubčinová, J.; Kozmon, S.; Šesták, S.; Baráth, M. ChemistrySelect 2020, 5, 4967-4972. doi:10.1002/slct.202001098

18. Poulin, M. B.; Zhou, R.; Lowary, T. L. Org. Biomol. Chem. 2012, 10, 4074-4087. doi:10.1039/c2ob25159k

19. Rose, N. L.; Zheng, R. B.; Pearcey, J.; Zhou, R.; Completo, G. C.; Lowary, T. L. Carbohydr. Res. 2008, 343, 2130-2139. doi:10.1016/j.carres.2008.03.023

20. Tvaroška, I. Carbohydr. Res. 2015, 403, 38-47. doi:10.1016/j.carres.2014.06.017

21. Fletcher, H. G., Jr.; Diehl, H. W. Carbohydr. Res. 1971, 17, 383-391. doi:10.1016/s0008-6215(00)82546-x

22. Joseph, C. C.; Regeling, H.; Zwanenburg, B.; Chittenden, G. J. F. Carbohydr. Res. 2002, 337, 1083-1087. doi:10.1016/s0008-6215(02)00100-3

23. Elchert, B.; Li, J.; Wang, J.; Hui, Y.; Rai, R.; Ptak, R.; Ward, P.; Takemoto, J. Y.; Bensaci, M.; Chang, C.-W. T. J. Org. Chem. 2004, 69, 1513-1523. doi:10.1021/jo035290r

24. Vembaiyan, K.; Pearcey, J. A.; Bhasin, M.; Lowary, T. L.; Zou, W. Bioorg. Med. Chem. 2011, 19, 58-66. doi:10.1016/j.bmc.2010.11.044

25. Lowary, T. L.; Li, J. Molecules 2016, 21, 1053. doi:10.3390/molecules21081053

26. Cocaud, C.; Maujoin, A.; Zheng, R. B.; Lowary, T. L.; Rodrigues, N.; Percina, N.; Chartier, A.; Buron, F.; Routier, S.; Nicolas, C.; Martin, O. R. Eur. J. Org. Chem. 2017, 6192-6201. doi:10.1002/ejoc.201701283

27. Cocaud, C.; Zheng, R. B.; Lowary, T. L.; Poisson, T.; Pannecoucke, X.; Nicolas, C.; Martin, O. R. Carbohydr. Res. 2018, 461, 45-50. doi:10.1016/j.carres.2018.03.009

28. Frigell, J.; Pearcey, J. A.; Lowary, T. L.; Cumpstey, I. Eur. J. Org. Chem. 2011, 1367-1375. doi:10.1002/ejoc.201001380

29. Li, J.; Lowary, T. L. Med. Chem. Commun. 2014, 5, 1130-1137. doi:10.1039/c4md00067f

30. Frédéric, C. J.-M.; Tikad, A.; Fu, J.; Pan, W.; Zheng, R. B.; Koizumi, A.; Xue, X.; Lowary, T. L.; Vincent, S. P. Chem. - Eur. J. 2016, 22, 15913-15920. doi:10.1002/chem.201603161

31. Dumitrescu, L.; Eppe, G.; Tikad, A.; Pan, W.; El Bkassiny, S.; Gurcha, S. S.; Ardá, A.; Jiménez-Barbero, J.; Besra, G. S.; Vincent, S. P. Chem. - Eur. J. 2014, 20, 15208-15215. doi:10.1002/chem.201404180 


\section{License and Terms}

This is an Open Access article under the terms of the Creative Commons Attribution License (http://creativecommons.org/licenses/by/4.0). Please note that the reuse, redistribution and reproduction in particular requires that the authors and source are credited.

The license is subject to the Beilstein Journal of Organic Chemistry terms and conditions:

(https://www.beilstein-journals.org/bjoc)

The definitive version of this article is the electronic one which can be found at:

doi:10.3762/bjoc. 16.152 